\title{
Minimising Risk-The Application of Kotter's Change Management Model on Customer Relationship Management Systems: A Case Study
}

\author{
Danny Sittrop and Cheryl Crosthwaite *(1) \\ Australian Institute of Management Business School, Sydney 2000, Australia; Dan.Sittrop@gmail.com \\ * Correspondence: Cheryl.Crosthwaite@aim.com.au; Tel.: +61-0404211345
}

check for

updates

Citation: Sittrop, Danny, and Cheryl Crosthwaite. 2021. Minimising Risk-The Application of Kotter's Change Management Model on Customer Relationship Management Systems: A Case Study. Journal of Risk and Financial Management 14: 496. https://doi.org/10.3390/ jrfm14100496

Academic Editor: Thanasis Stengos

Received: 25 August 2021

Accepted: 7 October 2021

Published: 17 October 2021

Publisher's Note: MDPI stays neutral with regard to jurisdictional claims in published maps and institutional affiliations.

Copyright: (c) 2021 by the authors. Licensee MDPI, Basel, Switzerland. This article is an open access article distributed under the terms and conditions of the Creative Commons Attribution (CC BY) license (https:// creativecommons.org/licenses/by/ $4.0 /)$.
Abstract: Implementing a Customer Relationship Management (CRM) system requires significant consideration with respect to change management and the associated business risks. This paper describes how to best achieve the change goal and minimize these risks. The research question under investigation is: "How can Kotter's change management model be used effectively to enhance the value and utilisation of a CRM system". Kotter's eight-stage change model is the adopted change model used by the organisation under study. As business intelligence (BI) is a growing field within industry and academia alike, limited substantive research has been done regarding how to manage the change process itself within a BI project. Often research either focuses on the technical development (e.g., agile methodology) or the change process from a holistic perspective. However, both are needed to effectively manage the risk of failure. The research design for this study was that of a single organisation case study. The research questions were addressed by using a deductive research style. To allow for multiple perspectives and triangulation of the data, a mixed-methods approach (Quant + QUAL) was used. Outcomes of the research showed that whilst there was some success in the implementation of Kotter's change model, it could have been significantly improved if the competencies identified in this research were considered and incorporated prior and during the change journey. Building on Kotter's classic work with change management, this research fills the gap by describing the pertinent competencies required in managing the change process, identifying common pitfalls and investigating the common threads between the 'data to outcome' process and the change management process to better mitigate the risk This paper adds value to current change literature/models by defining and describing the importance of these competencies when embarking on a change program related to BI tools and systems and how these competencies are incorporated into Kotter's model.

Keywords: change competencies; change management; CRM; Kotter's change model; risk; case study; business intelligence

\section{Introduction}

The success or failure of change management processes within an organisation has a direct impact on business risk and the associated financial outcomes (Kerzner 2018). The growing trend of using data to create customer value and inform business decisions, is forcing organisations to face the question of how to change to create data-driven value and, more importantly, how to execute the change successfully whilst minimising risk. Although there is no universally accepted definition of Business Intelligence (BI) (Nethravathi et al. 2020), it can be viewed as an umbrella term that includes the applications, infrastructure and tools, and processes that enable analytics of information to improve and optimise decisions, actions and performance (Hackney et al. 2015; Gartner 2021). Supporting BI is the Emergence of Industry 4.0, which has simultaneously created greater business opportunity through technologies such as artificial intelligence, cloud infrastructure, big data analytics and block-chain (Davis et al. 2020; Suler et al. 2021), and greater challenges with respect to 
its' implementation (Haskins et al. 2020; Cunningham 2021). Regardless of the increasingly critical need to understand the introduction of change, approximately seventy percent of all change projects fail (Kotter 1990; Beer and Nohria 2000; Higgs and Rowland 2005; Kotter 2007; Axelrod 2010). The inherent complexity within the emerging business intelligence (BI) discipline, coupled with the significant challenge of having a clear change goal in planned change, is making the change process for BI projects ambiguous at best and not adequately addressing the risk management issues. Trieu (2017) determined that there is a gap between BI value and the process of organisational change.

Many well-known change management models (Kotter 1996; Stacey 2001) have attempted to capture various change drivers, antecedents, and structures to ensure organisational success. Al-Haddad and Kotnour (2015) made the observation that different change methods need to be used for different change types, resulting in practitioners needing to be experts in the field to even consider implementation of these theories. Even with the copious amount of research done in the field, the pertinent link between change management theory and practice still needs significant development (Pollack and Pollack 2015) with a greater emphasis on producing research in a useable form for practitioners (Appelbaum et al. 2012). In today's competitive environment, it is even more imperative that there is a consideration of change and associated business risk (Misra et al. 2017).

This research paper is focused on a single case study of an organisation in the Automation Industry, which used Kotter's (1996) eight-stage model to assist with the implementation of their Customer Relationship Management (CRM) system. Specifically, the paper investigates how well Kotter's change model was applied through its implementation by reviewing the common pitfalls to change as defined by Kotter (2007) and then making recommendations on how Kotter's model could be adapted to increase the probability of success of the change program. The adaptions address the identified weaknesses in Kotter's model when attempting to introduce a CRM BI tool to the business. Current literature has analysed the efficacy of Kotter's model (Pollack and Pollack 2015; Kang et al. 2020). No research to date specifically examines a case organisation that uses Kotter's model in the context of BI and the implementation of BI tool(s). This research contributes to a better understanding of how Kotter's (1996) change management model needs adaptation in the context of a BI change program.

The first section summarises a literature review of change management, BI and risk. Following this, research questions and mixed methods methodology (QUAL + Quant) is outlined. Results from the research are provided in two parts. Firstly, the quantitative research is summarized to explain the level of CRM utilization after the change has been attempted within the case organization. Secondly, the larger portion of the research (qualitative) summarises the outcomes of thematic analysis to understand where improvements to Kotter's (1996) model could be made. The discussion section suggests a proposed adaption to Kotter's (1996) model when faced with a BI change program. The paper concludes with the managerial implications and overall contributions to existing literature.

Outcomes of the research showed that whilst there was some success in the implementation of Kotter's change model, it could have been significantly improved if the competencies identified in this research were considered prior and during the change journey. This paper adds value to current change literature/models by defining and describing the importance of these competencies when embarking on a change program related to BI tools and systems. Whilst the case study is in the Automation Industry; this research does not investigate the implications of BI on manufacturing processes (internal), but rather focuses on the implications of BI on the implementation of only the external customer data (CRM data).

\section{Literature Review}

Change approaches and styles can take many forms, depending on which theory is being observed. Change management theories can be viewed from an individual, team, and organisation level. The most discussed change management theories are at the 
organisational level (Kotter 1996; Stacey 2001), as leaders of organisations attempt to steer the entire company in line with their corporate or business level strategies. This is the focus of this paper.

Kotter's (1996) work, in particular, began to create a much-needed link between academic research and practitioners in order to translate research into a format usable by practitioners (Appelbaum et al. 2012; Kang et al. 2020). Step theories or models have attracted criticism (Kotter 2007; Laine et al. 2020). Despite this, Kotter's model is still of relevance today, with researchers using the model to consider change approaches in today's complex environment (Haas et al. 2020; Kang et al. 2020; Weiss and Li 2020; Chen 2021).

Any change model could be used for BI change initiatives; however, the change strategy must first be grounded in key business questions (Isson and Harriott 2012). Currently, many businesses are not clear about what they want out of a BI or artificial intelligence strategy (Williams 2011; Suler et al. 2021), or are struggling to get maximum value and insights from their data (LaValle et al. 2011; PricewaterhouseCoopers 2015), making commitment to these strategies hard, and implementation even harder. Hackney et al. (2015) believes that people's observations of the outcomes/impacts of using an information system are an antecedent to satisfaction. With many BI projects taking a longer period of time to complete, this suggests that the outcomes/impacts should be visible prior to the project completion. Yeoh and Popovic (2016) believe that a BI project needs a balanced team focusing on multiple areas such as IT and Business.

With the explosion of developments within the analytics discipline, businesses are trying to use data in functions such as produce/service development, manufacturing, marketing and sales, and risk management (Haskins et al. 2020; Suler et al. 2021) to either optimise internal processes (Davis et al. 2020; Cunningham 2021) and/or to gain a deeper understanding of the customer behaviour (Nethravathi et al. 2020). Often the root causes for failing change programs in these areas are internal challenges, such as skills gaps (Manyika et al. 2011; Williams 2011; Henke et al. 2016; Watson 2017), leadership understanding and support, effective technology infrastructure and tools, and alignment with corporate or business level strategies (Lapide 2014; Henke et al. 2016; Haskins et al. 2020). Furthermore, research done by Isson and Harriott (2012) of more than 100 companies showed that $37 \%$ indicated that their business intelligence function was not tightly aligned with the strategic priorities of the organisation.

\subsection{Kotter's Change Management Model}

Although aspects of Kotter's change management model are considered by many authors (Brisson-Banks 2010; Appelbaum et al. 2012; Pollack and Pollack 2015; Haas et al. 2020; Kang et al. 2020; Weiss and Li 2020; Chen 2021), no empirical studies to date, have been completed to critically analyse and critique the model in relation to BI practice. Thus, no scientific consensus has been reached to confirm or falsify its validity. Kotter's work is not isolated, with Todnem (2005) positing that change theories available to academics and practitioners alike are often lacking empirical evidence and are contradictory.

Through looking into each stage of Kotter's Model (Figure 1) in more detail, either direct or indirect support can be found.

Stage 1-Establishing a sense of urgency-has many authors' support (Garvin and Roberto 2005) by agreeing that there is a need for change recipients to believe there is a deviation from acceptable performance and therefore creating the need (urgency) for change.

The specific criteria of stage 2-Creating a guiding coalition-which includes Power, Expertise, Credibility and Leadership, has support in organisational change theories (Caldwell 2003). These theories either support having a coalition/team, utilising change agents, or address the criteria for creating a guiding coalition. 


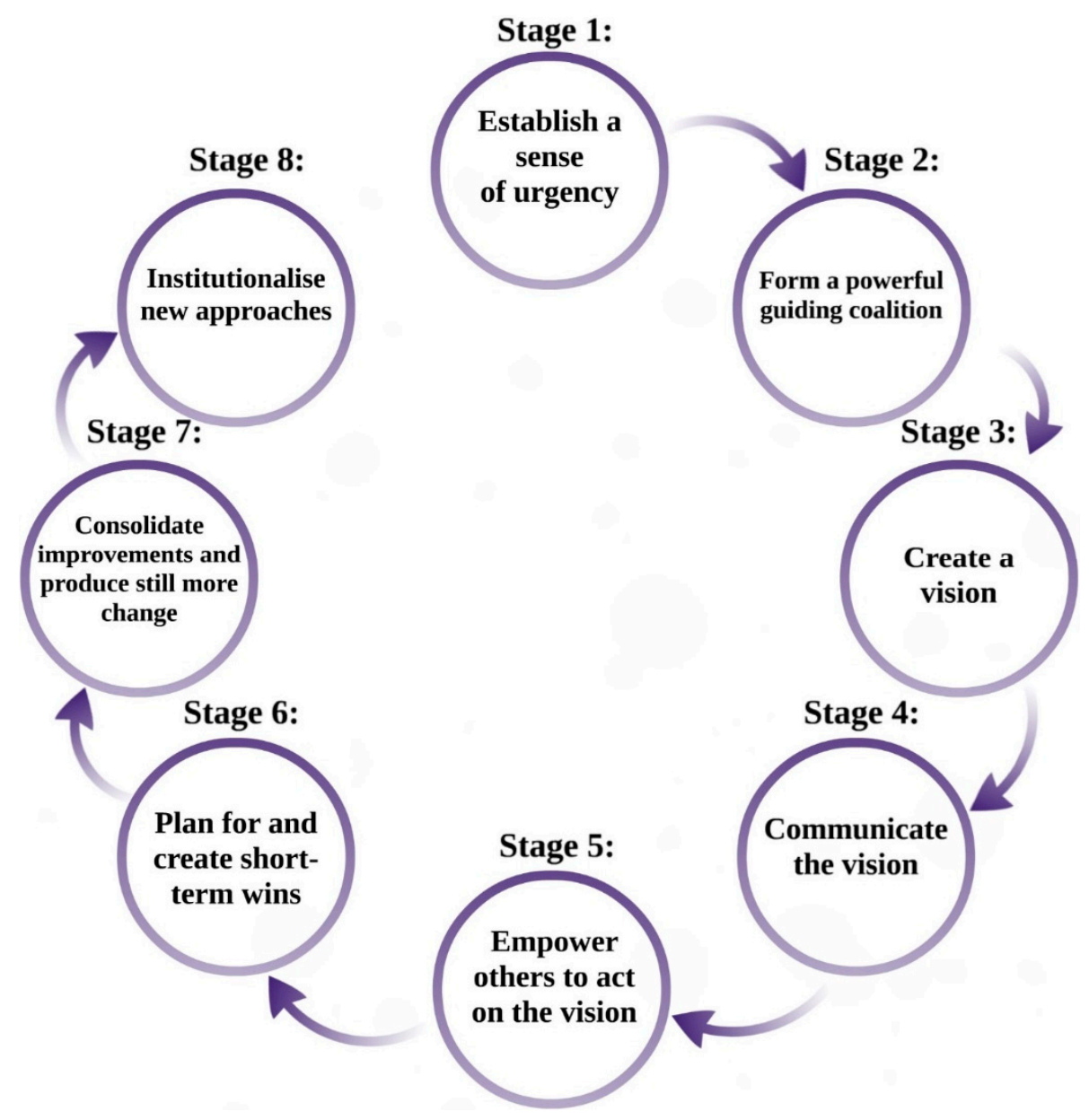

Figure 1. Adapted from Kotter's (1996) Change Stages.

Aligning with stage 3 - Creating the vision-and stage 4-Communicating the visionmost change models broadly accept the need to define and communicate what change is required to reduce uncertainty (Bordia et al. 2004) and decrease ambiguity (Nelissen and van Selm 2008). Nelissen and van Selm (2008) found significant correlations between employee satisfaction and management communication during organisational change. Kang et al. (2020, p. 2) suggest that: "major change is successful only when people buy-in and drive in the same direction, "and hence communication is required to achieve this. Appelbaum et al. (2012) identified support for Kotter's stage of communicating the vision.

In Stage 5-Empower others to act on the vision-Kotter (1996) addresses four major sources of major obstacles being structures, skills, systems, and supervisors. This stage also requires removing obstacles (Kang et al. 2020).

In stage 6-Planning for and creating short-term wins-there is limited evidence in the existing literature to directly support this stage. The literature does support some of Kotter's 'roles' of short-term wins, namely: reward change agents (Kouzes and Posner 2011), and undermine cynics and resistors (Fadzil et al. 2017). Lawler and Worley (2006) believed that when an organisation reverts back to a previous state and fails to anchor the change, the organisation is often worse off than if it had never attempted the change in the first place. Kotter addresses these points in stage 7-Consolidate improvements and still produce more change-and stage 8-Institutionalising new approaches. Wide support is given by many change management authors (Jacobs 2002), all concerning themselves with the sustainability of change, albeit from varying perspectives.

Diving into each stage individually, much support is available in existing academic literature. However, there are also a few general criticisms of Kotter's model. Appelbaum et al. (2012) suggested that Kotter's model is too rigid and does not capture the varying complex- 
ities of change. Pollack and Pollack (2015) found in their case study that an organisational change program required multiple concurrent instances of Kotter's process throughout the organisation due to the varying pace of each instance. Weiss and Li (2020, p. 739) argue that: "while Kotter presents his steps as linear, many steps can be iteratively modified".

\subsection{Change Management and Business Intelligence}

Currently, BI-related technologies are ranked among the top priorities for Chief Information Officers (CIOs) (Gaardboe and Svarre 2018). Haskins et al. (2020) concluded that $89 \%$ of survey respondents (from 4200 individuals involved in manufacturing) believed that they need to adopt digital technologies to prosper. With this emerging need of generating BI through data analytics, applying Kotter's model, without reframing the context through the lens of this emerging need, could result in poor outcomes for any change program designed to increase the level of BI through analytics.

Parallels can be drawn with the observations made within the literature and many of Kotter's (1996) steps (Table 1).

Table 1. BI and Kotter's Change Model—developed for this study.

\begin{tabular}{|c|c|c|}
\hline BI Literature & Kotter's Model & Linking Theme \\
\hline Skills Gaps. & $\begin{array}{l}\text { Empower others to act on the } \\
\text { vision. }\end{array}$ & $\begin{array}{l}\text { Concerned with the technical } \\
\text { capacity of people to enact the } \\
\text { change required. }\end{array}$ \\
\hline \multirow{2}{*}{$\begin{array}{l}\text { Leadership Understanding \& } \\
\text { Support. } \\
\text { Creating a balanced team. }\end{array}$} & $\begin{array}{l}\text { Establishing a sense of } \\
\text { urgency. }\end{array}$ & $\begin{array}{l}\text { Concerned with creating a } \\
\text { need for change within the } \\
\text { leadership team(s). }\end{array}$ \\
\hline & $\begin{array}{l}\text { Form a powerful guiding } \\
\text { coalition. }\end{array}$ & $\begin{array}{l}\text { Having the right team being } \\
\text { agents for change, which } \\
\text { include a balance of people } \\
\text { across the organisation. }\end{array}$ \\
\hline $\begin{array}{l}\text { Effective technology, } \\
\text { infrastructure and tools. }\end{array}$ & $\begin{array}{l}\text { Empower others to act on the } \\
\text { vision. }\end{array}$ & $\begin{array}{l}\text { Concerned with having the } \\
\text { right structure and systems in } \\
\text { place to facilitate change. }\end{array}$ \\
\hline \multirow{2}{*}{$\begin{array}{l}\text { Alignment with corporate or } \\
\text { business strategies. }\end{array}$} & Create a vision. & $\begin{array}{l}\text { The change vision needs to be } \\
\text { part of the corporate or } \\
\text { business strategies. }\end{array}$ \\
\hline & Communicate the vision. & $\begin{array}{l}\text { Communications of the } \\
\text { corporate or business level } \\
\text { strategies should include the } \\
\text { change vision. }\end{array}$ \\
\hline
\end{tabular}

Outcomes/impacts of using the system is an antecedent to satisfaction.

Breaking a large project into

Generating short-term wins.

If leaders cannot show positive outcomes quickly, it will reduce satisfaction.

smaller ones.

Applying an effective BI change management project also requires businesses to understand what the Key Success Factors (KSFs) are, which will underpin successful implementation (Gaardboe and Svarre 2018) and minimise the risk of failure or less effectiveness. Several authors have completed a meta-data analysis of key success factors which influence information systems in general. The most predominant themes include overall system performance, net benefits of the user, and information quality (Hackney et al. 2015; Yeoh and Popovic 2016; Gaardboe and Svarre 2018). These results show that any change management project should have a heavy user-oriented perspective, which has been addressed more in recent times with the evolution of 'Agile' ways of working. Varying agendas of different stakeholders and their subsequent beliefs regarding the success of a BI project 
(Urbach et al. 2009), also reinforces the need to ensure the users' needs are focused on not just a single stakeholder.

\subsection{Change Management and Risk}

Identifying planned change inevitably means there is risk to be considered (Kerzner 2018). Stare (2011, p. 72) suggested that the "processes of managing change are incontestably relevant" and need to be included in the process of risk management. Risk management can be considered part of change management (Misra et al. 2017). Apostolopoulos et al. (2016) suggest that many project methodologies fail to address risk in change management. A risk management focus is embedded in change management when there is a focus on resistance to, and management of, change (Stare 2011; Apostolopoulos et al. 2016). Stare (2011, p. 83) concludes that the combined functions of risk and change management: "enables the more efficient management of changes to ensure better achievement of project objectives".

\section{Materials and Methods}

\subsection{Research Questions and Aim}

The research question for this study is, how can Kotter's (1996) change management model be used effectively to enhance the value and utilisation of a CRM system? The overall research aim is to minimise the risk of poor business decision-making by more effectively using the organisations' adopted change management model.

To achieve this aim, the following sub-questions have been identified:

1. What is the current CRM utilisation?

2. What is the ideal state of CRM utilisation?

3. How can the organisation better manage the change using Kotter's model as the foundation?

The first research question was seeking to establish a baseline. This was then followed up by answering whether (and to what extent) Kotter's model was followed and implemented. The last was determining how the organisation can better implement the change process in the future to minimise risk and maximise the probability that the change is institutionalised.

\subsection{Participants Involved in the Research}

In total, seventeen participants, from three different levels $(6 \times$ Senior Management, $4 \times$ Middle Management and $7 \times$ Functional Team) across six departments of the organisation, contributed to the data collection that ensured an accurate 'weighted' representation of those that either used CRM or were responsible for its use and development.

Sampling was done using a stratified random sample selection method (Saunders et al. 2019). The population was purposefully divided to capture the heterogeneity in the department and by organisational hierarchy (role level). Within each department and level, a random selection of participants was selected, with the total number of participants in each group adjusted by the level of involvement with the CRM tool.

Although there were a limited number of respondents, planning for detailed interviews with each respondent enabled a high level of depth and richness from the data collected.

\subsection{Methodology}

\subsubsection{Research Design}

The research design is based on a descriptive approach to gain an accurate profile of current and desired level of CRM utilisation; then, an evaluative study to find out how effectively the desired level of CRM utilisation was reached (Saunders et al. 2019). The descriptive component is a quantitative analysis that answers research questions one and two, whereas the evaluative component is a qualitative analysis which answers question three. With the sequential mixed methods (Quant + QUAL) approach (Saunders et al. 2019), qualitative analysis is the major component of the research. 
The research design for this study is a single organisation case study (Yin 2017) which seeks to understand the dynamics of the organisation's selected change management model within the context of a sales organisation (Eisenhardt and Graebner 2007). The study employed a deductive research style (Bell et al. 2019) to understand to what extent the propositions can be confirmed or rejected. The mixed-methods approach allows for multiple perspectives and triangulation of the data (Saunders et al. 2019). Methods to limit systematic biases and chance associations included purposeful sampling, triangulation, individual coding, and quoting comments verbatim (Maxwell 2013).

\subsubsection{Measures and Data Collection}

Quantitative analysis summarises the actual CRM utilisation level against the desired level of CRM utilisation by department and hierarchy after the change had been attempted.

Following this, semi-structured interview questions for the qualitative analysis elicited information about each stage of Kotter's model related to the pitfalls in change management that Kotter (2007) identified, resulting in rich information detailing how the change process was managed and where improvements could be made. All interviews were conducted in a neutral environment, recorded, and transcribed for thematic analysis by coding (Saunders et al. 2019) and production of major and minor themes.

\subsubsection{Ethical Considerations}

Due to considerations of participants potentially limiting their responses in fear of specific information about them being reported to upper management levels, all analysis, reports and publications generated from this project did not include individual names. Each of the interviewee's transcriptions was given a code for the purposes of performing the analysis by department and hierarchy. The transcriptions were completed by an independent party and did not store or keep any of the recordings and conform to the quality and security standards expected by an academic research project. No information was asked that could be potentially sensitive or harmful to the individual within the context of the workplace. Furthermore, the consent form, which has been acknowledged and signed by each participant outlines the additional precautions taken to protect each participant.

Although holistically, the AMSRS Standards needed to be followed (The Research Society 2021), specifically the following points are pertinent to this project:

1. Participation was voluntary and consent forms had to be signed.

2. Appropriate confidentiality throughout the process of collection, storage, analysis and reporting was maintained. This included limits to the granular level of data made available to other employees in the case organisation.

3. Surveying and interviewing were done as anonymously as possible. Where association was necessary, surveys were coded.

Ethics approval was granted for this research through the Australian Institute of Management Business School Ethics Committee.

\subsubsection{Limitations}

Due to practical limitations, the scope and size of the project and methodological strategies, there are several limitations and associated assumptions:

1. The methodology did not allow for a natural science positivism philosophy because the results of the data needed to be more flexibly interpreted to address the research questions. Moreover, the objective of the research is not to define cause and affect relationships but to understand individuals' interpretations of a phenomenon so that future behaviour can be influenced in line with the strategic direction of the organisation. Thus, a more interpretivist epistemological approach is taken where the researcher is more concerned with the empathic understanding of human action rather than the forces that act on it (Bell et al. 2019). While this does limit the outcomes of empirical evidenced-based cause and effect relationships, the results will 
provide a better understanding of current phenomenon that are occurring and clear recommendations for future actions based on the perspectives of the participants to the research.

2. Limited to one organisation as a specific case study. Due to this, the results are not generalizable to other settings or groups of a similar context.

3. The research assumes that the functions of CRM will not change and that the research question is only addressing the implementation and utilisation of the set CRM functions. Reality of the digital era dictates that these functions could change and/or adapt over a short period of time. This could change the responses within the questionnaires and interviews. However, the research can only consider current and not future possibilities.

4. Although the CRM functions cover most of the functionality with the CRM system, there are other areas within the software program that were not included as it would significantly increase the size of the project to an impractical level.

5. Due to the researcher's role as the 'CRM Key User', there may be an internal bias represented by the researcher's personal views surrounding this topic. This has been communicated prior to each data collection point and personal views were not communicated during any data collection.

6. An external researcher may yield different outcomes due to the unfamiliarity of the topic in comparison to the current researcher, particularly in providing clarity to CRM processes and areas of the semi-structured interview.

7. Due to the fact existing theory is being used, and applying a deductive approach to the qualitative data analysis, this could restrict the value of the data by not also incorporating an inductive approach to the analysis (Yin 2017).

8. Some of the senior management members have cross-functional responsibilities. Due to the types of analysis completed, each respective EMT member with multiple responsibilities was designated under only one of their departmental responsibilities so that ensuing analysis could be done accurately, without duplicating results across departments.

\section{Results}

Customer data is potentially one of the most important collections of information for the case organisation. CRM represents a 'shadow' of their marketplace where they can draw insights about customer behavior and apply marketing automation techniques; therefore its correct utilisation is paramount.

\subsection{CRM Utilisation}

Through the survey, each respondent answered questions regarding which department should utilise each specific CRM function and whether they themselves utilise the function. Aggregating this data, we were able to establish the desired and actual utilisation for each CRM function by department. Current CRM utilisation results described an organisation with an inconsistent level of utilisation across department and hierarchy, indicating that that the implementation of Kotter's change model was not successful. Figure 2 below indicates the level of each department's utilisation had compared with the desired level of CRM utilisation for each department. 


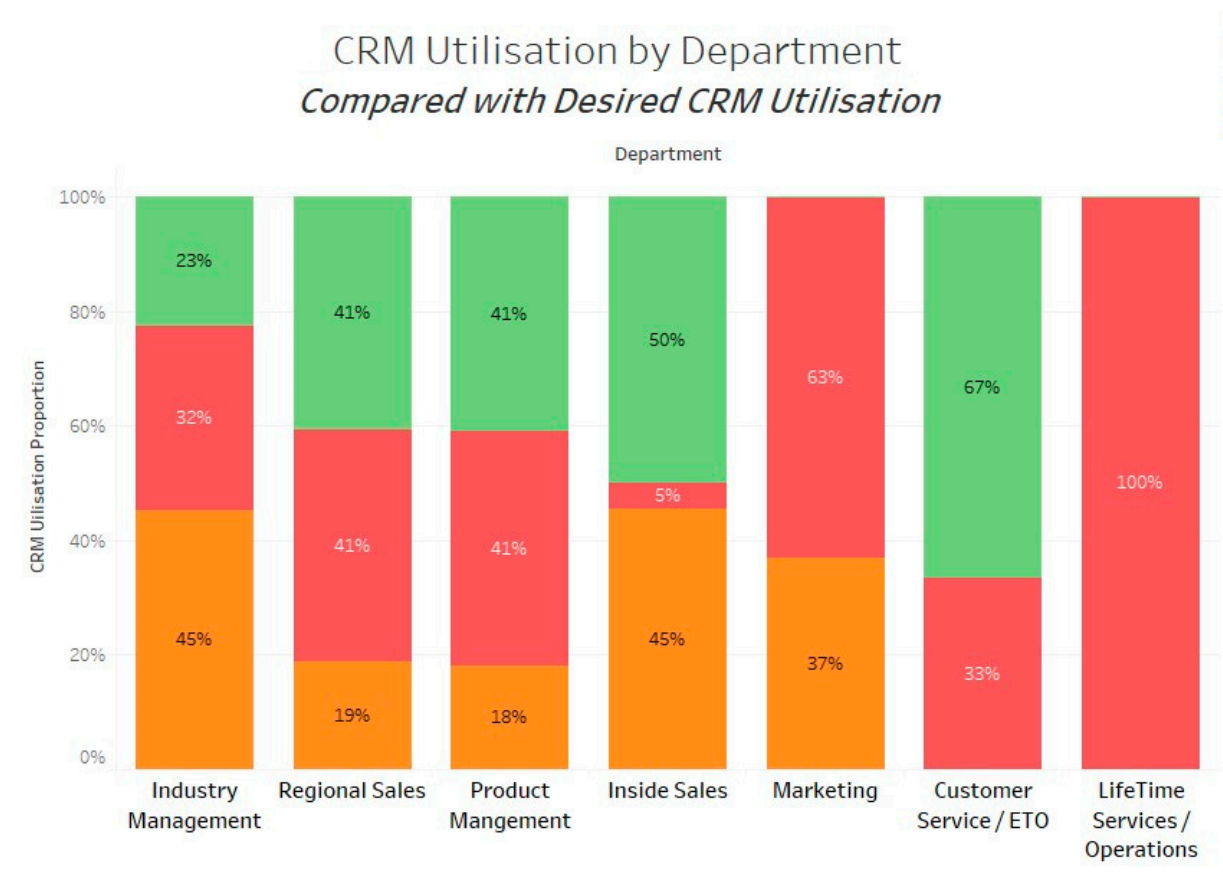

Figure 2. Level of CRM actual utilisation against desired utilisation by function and departmentdeveloped for this study.

Based on the gaps in the desired utilisation, we were able to look deeper into whether a difference in utilisation exists between hierarchies within the business by analysing the variance of utilisation for each CRM function between the organisational hierarchies. ${ }^{1}$ Firstly, Figure 3 below illustrates specifically which CRM processes had a low variance.

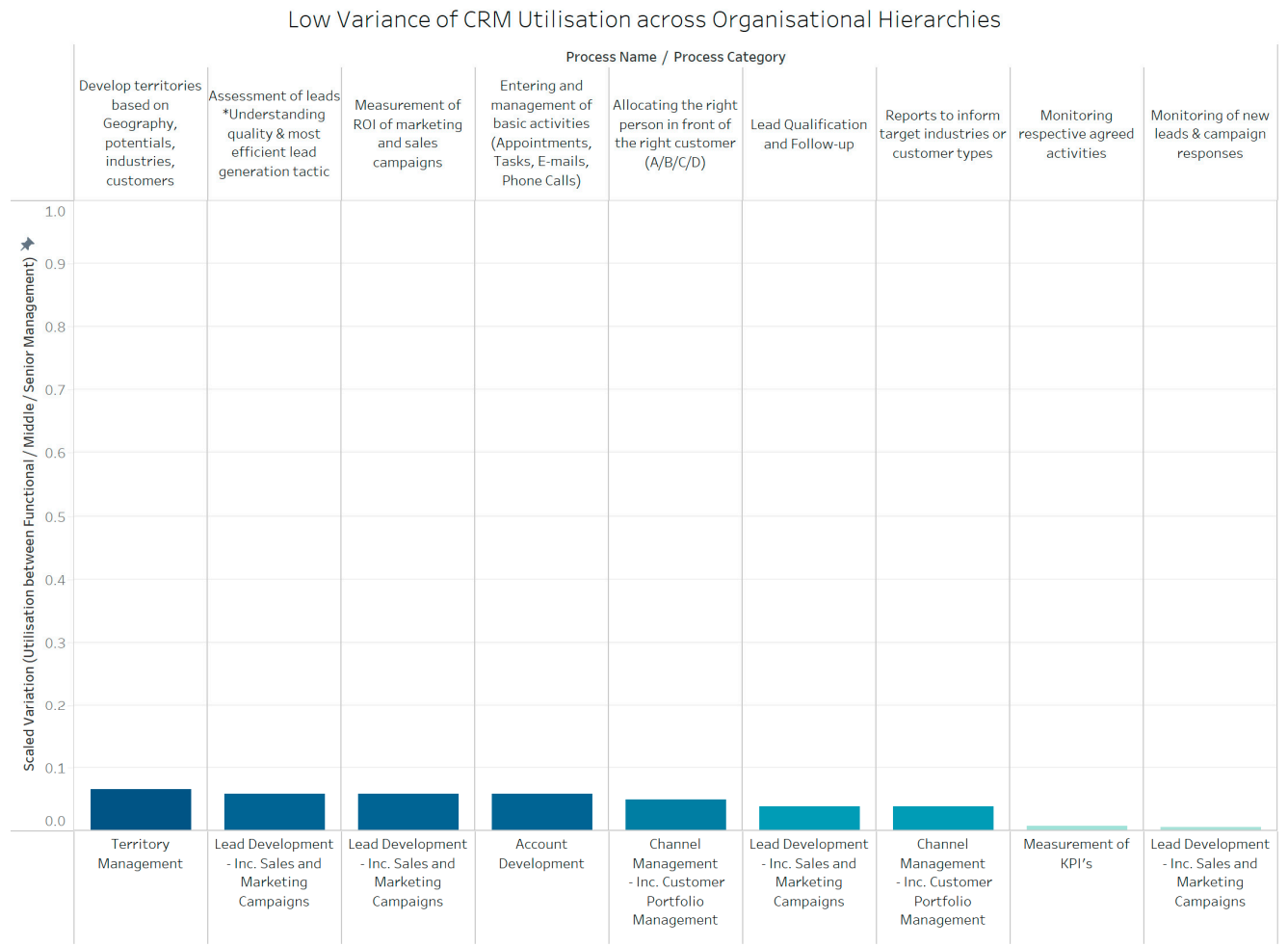

Figure 3. CRM Processes with a high variance of utilisation across organisational hierarchies, as developed for this study. 
Secondly, Figure 4 below illustrates CRM processes with a medium variance.

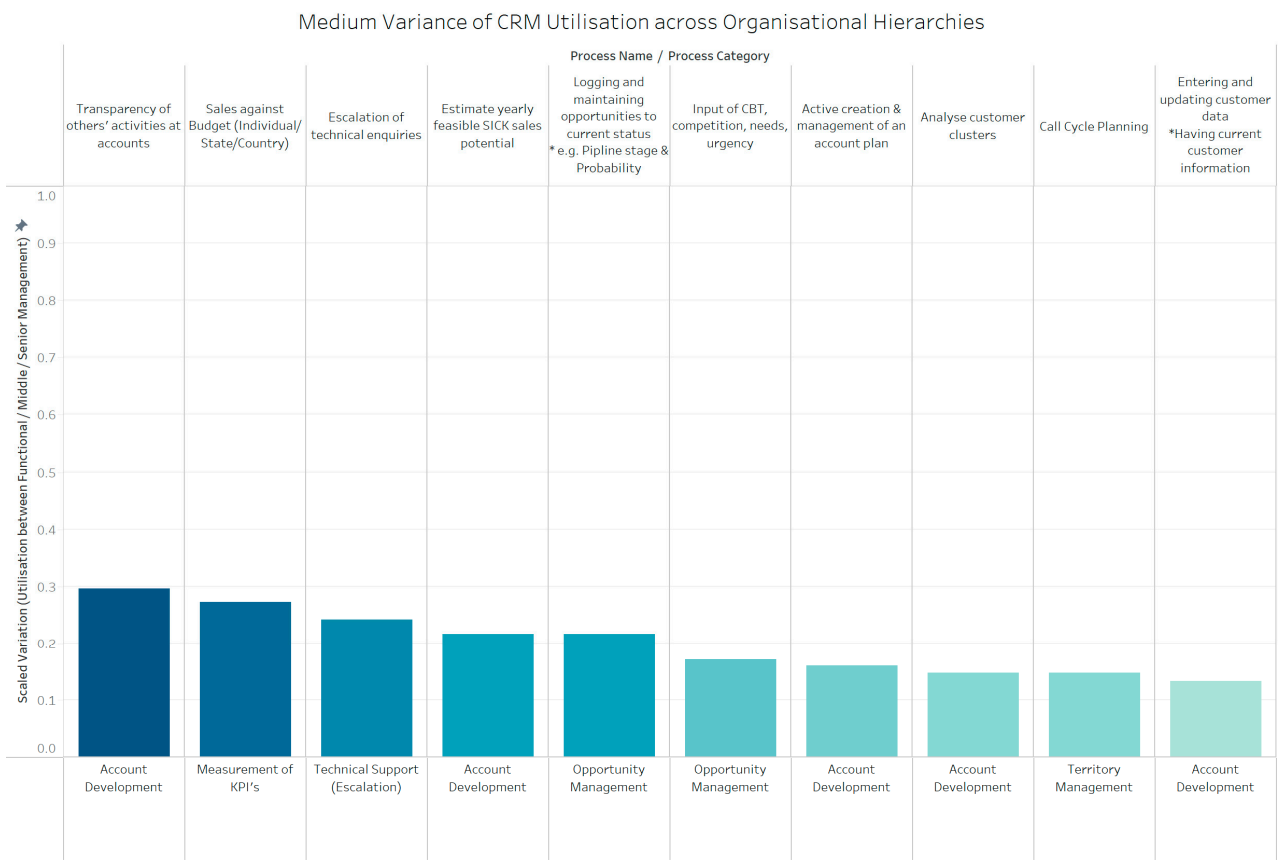

Figure 4. CRM Processes with a high variance of utilisation across organisational hierarchies, as developed for this study.

Finally, Figure 5 below illustrates CRM processes with a high variance.

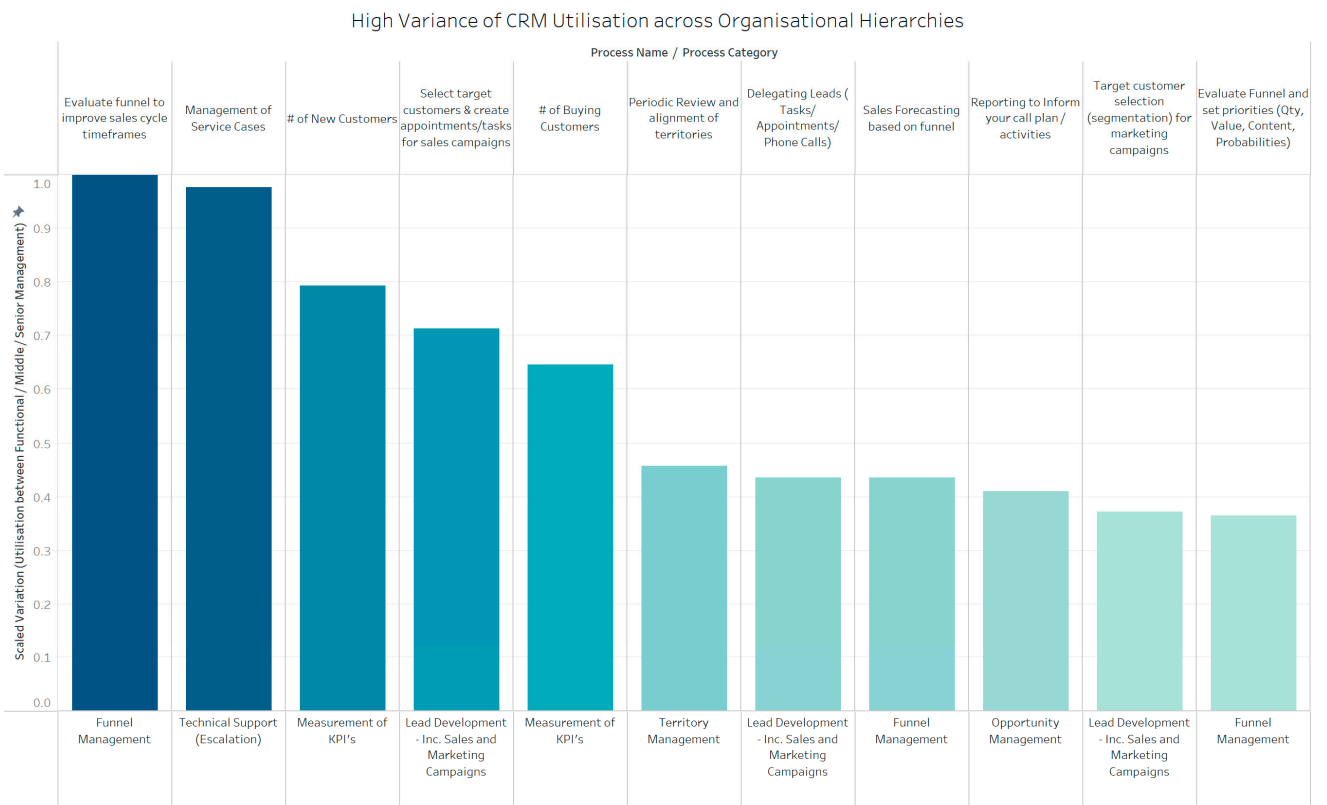

Figure 5. CRM Processes with a high variance of utilisation across organisational hierarchies, as developed for this study.

These charts describe an organisation that not only has inconsistent utilisation of CRM across departments, but also across hierarchical levels, which supports the assertion that CRM is not being utilised in the desired way.

These identified gaps prove that the change was not successful using Kotter's model, either due to the poor implementation of the model or due to elements which Kotter's 
model does not account for when considering BI tool implementations. Confirmation the change was unsuccessful initiated the qualitative research to understand why these results were seen and how improvements could be made.

\subsection{Major Themes When Implementing CRM}

Eighteen major themes were coded from the interviews, which provides direction towards how the organisation managed the known pitfalls of Kotter's (2007) change management process. These themes indicate what is most important when implementing a CRM system through Kotter's (1996) change management model. The themes, definition and supporting verbatim comments are presented in Table 2 below.

Table 2. Major themes created in the thematic analysis of semi-structured interviews.

\begin{tabular}{|c|c|c|}
\hline Theme & Frequency & Definition \\
\hline $\begin{array}{l}\text { Useable \& Meaningful data } \\
\text { “...you need to make the data useable and be able to easily get the } \\
\text { data out in a human interpretable form so that it becomes useful to } \\
\text { people."-Respondent WRE } \\
\text { “... allow them to see how they can take that big amount of data } \\
\text { they've got there that they spent half of their sales life entering and } \\
\text { actually use it to generate more sales..."-Respondent DRM }\end{array}$ & 47 & $\begin{array}{l}\text { If the data in CRM is useful and } \\
\text { meaningful, then users will see the } \\
\text { benefit in it. }\end{array}$ \\
\hline $\begin{array}{l}\text { Consistent \& Clear Communication } \\
\text { "... it was a little bit of a one-hit wonder, where there was a very short } \\
\text { cycle of intensity and then nothing ... "- - Respondent BIF } \\
\text { "...it's communication is the key, yes. So, if there's change, you can't } \\
\text { individually."- Respondent CRF }\end{array}$ & 36 & $\begin{array}{l}\text { To communicate the vision or strategy of } \\
\text { CRM consistently and clearly. }\end{array}$ \\
\hline $\begin{array}{l}\text { Heterogeneous use of CRM } \\
\text { "Everyone seems to be just doing their own thing."-Respondent CPF } \\
\text { "Right now I just look at it and go OK, that's their thing, this is our } \\
\text { thing, not my problem."-Respondent CCM }\end{array}$ & 35 & $\begin{array}{l}\text { Not yet reached full implementation of } \\
\text { the CRM vision. }\end{array}$ \\
\hline $\begin{array}{l}\text { No full CRM implementation and/or utilization } \\
\text { "...we're not using to its full potential, CRM."-Respondent EMF }\end{array}$ & 34 & $\begin{array}{l}\text { Not yet reached full implementation of } \\
\text { the CRM vision. }\end{array}$ \\
\hline $\begin{array}{l}\text { CRM efficiency } \\
\text { "It takes a long time to enter a very simple piece of } \\
\text { information."- - Respondent KPM }\end{array}$ & 31 & $\begin{array}{l}\text { Related to the overall efficiency of the } \\
\text { CRM tool. }\end{array}$ \\
\hline $\begin{array}{l}\text { Increasing visible benefits of CRM } \\
\text { "...what is it, what are the things it'll do, and what's in it for me at } \\
\text { the end of the day."-Respondent WIE }\end{array}$ & 31 & $\begin{array}{l}\text { Working on showing the benefits of } \\
\text { entering the data. }\end{array}$ \\
\hline $\begin{array}{l}\text { Hard approach to change management } \\
\text { "There has to be a balance between carrot and stick. Neither of the } \\
\text { two are going to work and neither of the two will work } \\
\text { alone."-Respondent TIE } \\
\text { Negative Mindset/Attitude }\end{array}$ & 27 & $\begin{array}{l}\text { CRM is viewed as a tool to manage } \\
\text { performance and/or the message to use } \\
\text { CRM has a directive top-down approach. }\end{array}$ \\
\hline $\begin{array}{l}\text { "And as well as the understanding of the reporting regime for the } \\
\text { greater good rather than evil, and I still think that's a sales } \\
\text { management topic that needs to be done."-Respondent DDE }\end{array}$ & 25 & $\begin{array}{l}\text { When people view CRM through a } \\
\text { negative bias lens. }\end{array}$ \\
\hline $\begin{array}{l}\text { The Why } \\
\text { "I believe we need a, a leader who will actually put a picture in } \\
\text { people's head to understand why we're doing it."-Respondent BIF }\end{array}$ & 25 & $\begin{array}{l}\text { Understanding the underlying purpose } \\
\text { and need for an effective CRM. }\end{array}$ \\
\hline $\begin{array}{l}\text { Change in organisational roles } \\
\text { "I don't think anybody in our organisation is really driving the } \\
\text { change in CRM."-Respondent TIE }\end{array}$ & 20 & $\begin{array}{l}\text { Expression of a need to change the roles } \\
\text { and or responsibilities of employees. }\end{array}$ \\
\hline $\begin{array}{l}\text { Knowledge Management } \\
\text { "And to have a culture where any discussions around any } \\
\text { opportunities, any successes, et cetera, are documented and are able } \\
\text { to be extracted from CRM at any given time."-Respondent MME }\end{array}$ & 18 & $\begin{array}{l}\text { Identifying, capturing, evaluating, } \\
\text { retrieving, and sharing everything } \\
\text { within CRM. }\end{array}$ \\
\hline
\end{tabular}


Table 2. Cont.

\begin{tabular}{|c|c|c|}
\hline Theme & Frequency & Definition \\
\hline \multicolumn{3}{|l|}{ Performance Management } \\
\hline $\begin{array}{l}\text { "We must be using properly every day because it helps us personally } \\
\text { keep track of our goals and so we rely on the } \\
\text { information."-Respondent CRF }\end{array}$ & 15 & $\begin{array}{l}\text { How CRM affects the performance } \\
\text { management of employees. }\end{array}$ \\
\hline $\begin{array}{l}\text { Teamwork } \\
\text { “It's pretty simple—just interact more."-Respondent KPF }\end{array}$ & 13 & Discussing elements of teamwork. \\
\hline \multicolumn{3}{|l|}{ Milestone Successes } \\
\hline $\begin{array}{l}\text { "Look, in some cases, it's being used very well and I see good insight } \\
\text { come out of it in terms of where we're going to attack next or what } \\
\text { our motivations are for doing a certain thing."-Respondent DRM }\end{array}$ & 13 & $\begin{array}{l}\text { When the organisation has realised an } \\
\text { achievement towards the change goal. }\end{array}$ \\
\hline Implementing new ideas & & Implementing new ideas and \\
\hline $\begin{array}{l}\text { “...something that's really important for us moving forward is } \\
\text { around spending time around ideation, just creating } \\
\text { ideas."-Respondent WIE }\end{array}$ & 12 & $\begin{array}{l}\text { communicating this out to the } \\
\text { organisation to encourage more creative } \\
\text { thinking. }\end{array}$ \\
\hline \multicolumn{3}{|l|}{ Clear set of goals } \\
\hline $\begin{array}{l}\text { "... So if we talk about the shortcomings, I believe what we can do is, } \\
\text { first of all, have some short-term goals."-Respondent KPF }\end{array}$ & 9 & Developing and defining clear goals. \\
\hline $\begin{array}{l}\text { No sense of urgency } \\
\text { "So unless there is some kind of motivation for them to utilise } \\
\text { something like CRM, there's no reason for them."-Respondent DRM } \\
\text { No clear vision }\end{array}$ & 6 & $\begin{array}{l}\text { No sense of urgency throughout various } \\
\text { parts of the organisation. }\end{array}$ \\
\hline $\begin{array}{l}\text { "What is the vision? Does anyone know what the vision is of CRM } \\
\text { other than the statement it is the main repository for all customer } \\
\text { interactions?"-Respondent MME }\end{array}$ & 4 & $\begin{array}{l}\text { When there is no clear understanding of } \\
\text { the vision for CRM. }\end{array}$ \\
\hline
\end{tabular}

Developed for this study.

Displaying these themes, Table 3 below summarises the top three major themes discussed at each stage of Kotter's change model. Apparent is that some of the most discussed themes appear in multiple stages of Kotter's (1996) stages. For example, 'useable and meaningful data' was highlighted by the respondents when discussing Stage 1, Stage 3 and Stage 8.

Table 3. Top three major themes at each stage of Kotter's (1996) change process.

\begin{tabular}{ll}
\hline Stage 1: Establish a sense of urgency & Stage 2: Form a powerful guiding coalition \\
(a) Useable and meaningful data. & (a) Change in organisational roles. \\
(b) The 'Why'. & (b) Teamwork. \\
(c) Knowledge Management. & (c) Heterogenous use of CRM.
\end{tabular}

\section{Stage 3: Create a vision}

(a) Useable and meaningful data.

(b) CRM efficiency.

(c) Heterogenous use of CRM.

\section{Stage 4: Communicate the vision:}

(a) Consistent and clear communication.

(b) Hard approach to change management.

(c) Increasing the visible benefits of CRM.
Stage 5: Empower others to act on the vision
(a) No full CRM implementation and/
(b) CRM efficiency.
(c) Increasing the visible benefits of CRM.

Stage 7: Consolidate improvements and produce still more change
(a) Milestone successes.
(b) No full CRM implementation and/or utilisation.
(c) Hard approach to change management.

\section{Stage 6: Plan for create short-term wins:}
(a) Negative mindset/attitude.
(b) Implementing new ideas.
(c) Consistent and clear communication.

Stage 8: Institutionalise new approaches:
(a) Useable and meaningful data.
(b) Consistent and clear communication.
(c) The 'Why'. 
Research outcomes show that three major themes are the most important to the successful implementation and utilisation of a CRM tool by use of Kotter's (1996) change model. These three themes, namely 'Useable and meaningful data', 'Consistent and clear communication' and 'Heterogeneous use of CRM', represent $30 \%$ of the discussed themes from the collected data (Figure 6).

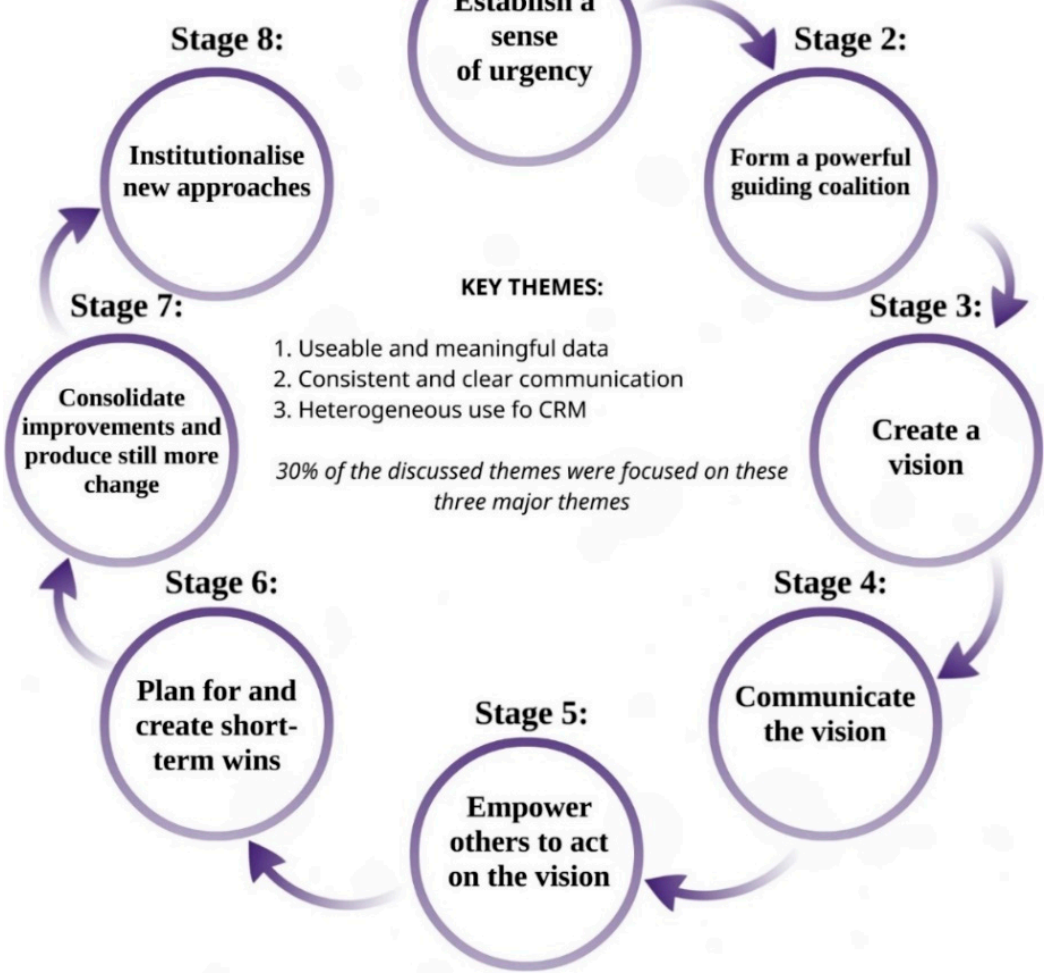

Figure 6. Three top major themes discussed in the interviews. Adapted from Kotter's (1996) model.

These themes add to the current body of literature when trying to understand the root causes of failed change programs in the BI context. 'Useable and meaningful data' expresses a lack of understanding regarding how the data can be a benefit to the individual or business. This theme also shows that there is a lack of context around the data which would provide meaning and therefore influence decision making. While this is related to the skills gap challenge identified earlier, this theme hones in on an overall lack of data literacy. Communication plays a significant role in Kotter's (1996) model; however, it was still a consistent topic when discussing the pitfalls across all of Kotter's (1996) stages within the theme 'Consistent and Clear Communication', suggesting that communication needs to be further bolstered through many more stages of the process. The third theme, 'Heterogeneous use of CRM', identifies an inconsistent understanding of the CRM tool across the case organisation. Many factors could influence how the CRM is being utilised; however, the respondents were looking for a more homogeneous view of CRM to enable a consistent approach to training and day-to-day engagements with CRM.

Figure 7 below shows a nearly equal dispersion of these themes across department and hierarchy, which illustrates common concerns and/or perspectives on the implementation and utilisation of the CRM tool. Anomalies to this include Lifetime services/Operations from a departmental perspective and the Extended Management Team from the hierarchical perspective. The hierarchical summary also shows that the higher you look in the hierarchy, the less important these themes become. 

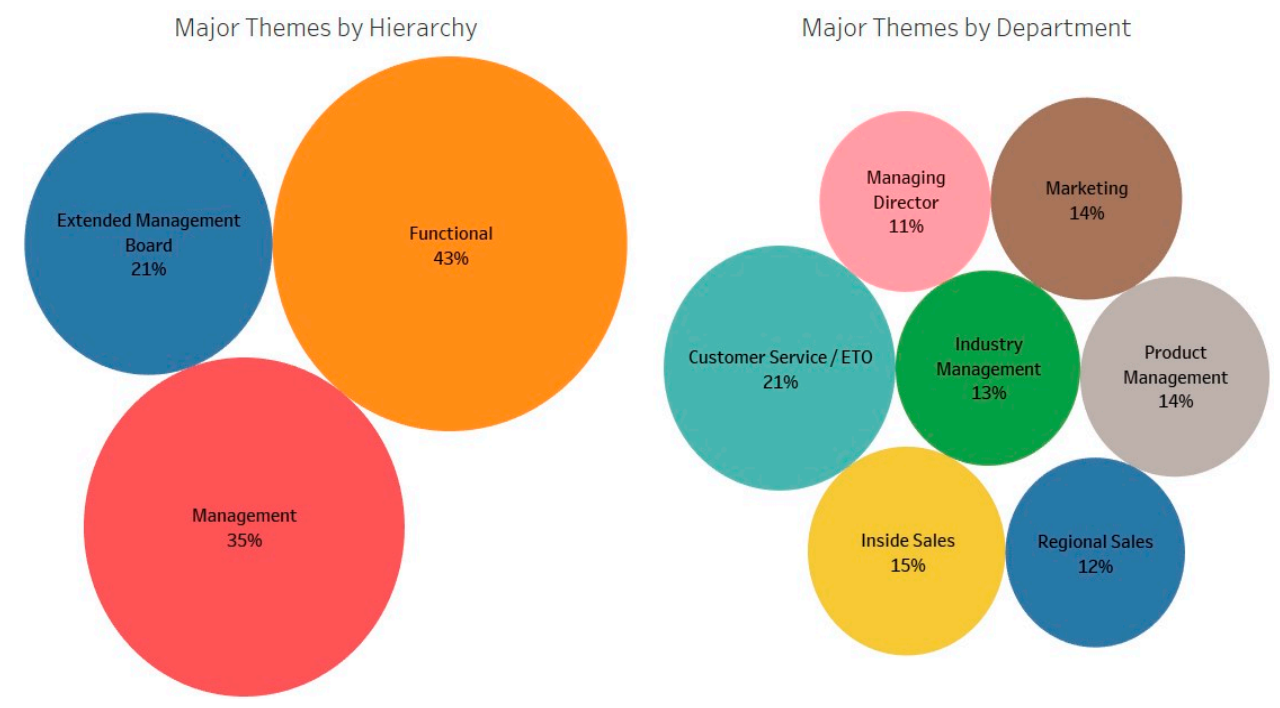

Figure 7. Major Themes' importance by department and hierarchy, as developed for this study.

\subsection{Competencies Required}

From the thematic analysis, five competencies were identified which provide clear insight into the perceptions of antecedents to successful CRM BI change management projects. These competencies address most of the feedback from respondents related to why the change program failed. In total, $46 \%$ of the coded feedback directly supported one of these five identified competencies required to successfully implement a CRM BI Program (Figure 8). The volume of feedback directly provided input into the creation of the competencies, and describes their importance when engaging in a CRM change program. Additionally, each competency had input from almost all stages of Kotter's (1996) change model during the semi-structured interviews. This is consistent with the extant literature (LaValle et al. 2011; Manyika et al. 2011; Williams 2011; Isson and Harriott 2012; Lapide 2014; Hackney et al. 2015; PricewaterhouseCoopers 2015; Henke et al. 2016; Yeoh and Popovic 2016; Watson 2017; Gaardboe and Svarre 2018; Haskins et al. 2020).

\section{Competencies by Kotter's stages}

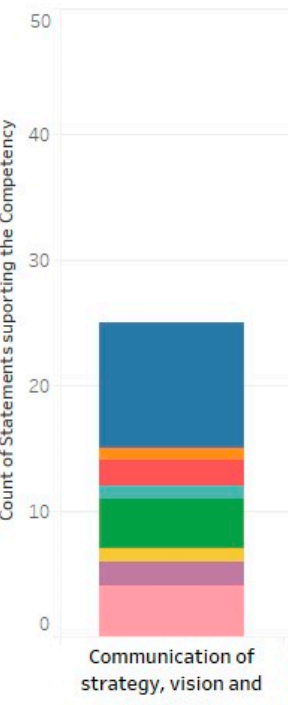

Skill

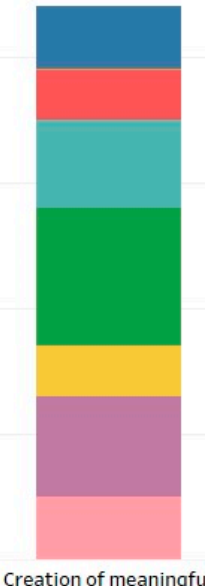
Creation of meaningful Delivering visible understanding of business processes
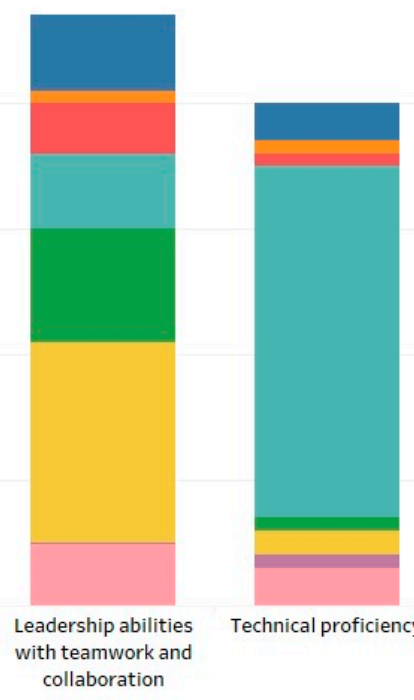

Kotters stages

Communicating a vision

Consolidate improvement and still produce more change

Creating a vision

Empowering others to act

Establishing a sense of urgency

Forming a powerful guiding coalition

Institutionalising new approaches

Plan for and create short term wins

Figure 8. Top five competencies identified-developed for this study. 


\section{Discussion}

These results emphasized several key competencies that need to be developed in the implementation of Kotter's (1996) change model when applying it to a Business Intelligence strategy such as CRM to better minimise risk and allow for greater success. Although the eight stages of Kotter's (1996) model are well accepted, when applying it to a CRM BI strategy, these competencies need to be addressed as key influences for the success of the change project.

\subsection{Revision of Kotter's Model to Include CRM BI}

Using the results from the qualitative research, Figure 9 below illustrates the proposed adaption to Kotter's change model when considering a CRM BI change project. Each of the competencies need to be applied across various stages as shown above and, therefore, it is important for people involved in different stages of the change to have the required competencies. The outcomes of this study infer, at a minimum, the guiding coalition, between its members, be competent in all required competencies. Failure to achieve this will put at risk the quality of CRM implementation, subsequent business decisions and therefore put at risk the overall business success. Kotter's (1996) model is a stepwise process which begins at Stage 1 and ends at Stage 8. From the thematic analysis, an adapted version of this process has been created with a cyclical, hub and spoke topology. This topology allows the business to re-start the process as many times as necessary as some steps may need repeated and/or to be strengthened. The hub and spoke component ensure that the competencies are applied as required across all stages of the change process.

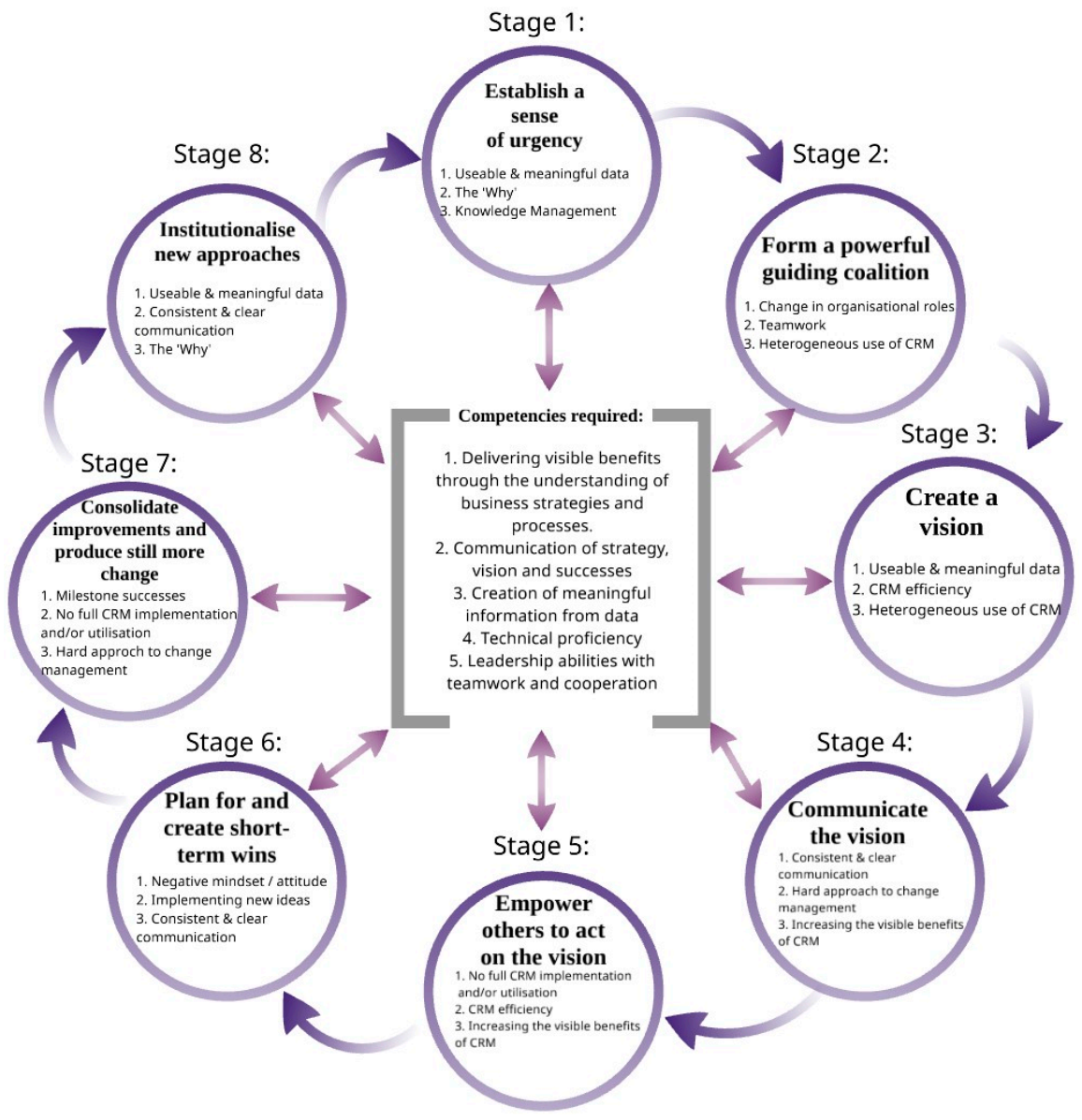

Figure 9. Adapted version of Kotter's change model (Kotter 1996) for BI change projects.

The spectrum of these identified competencies ranges from hard technical skills to soft, people-oriented skills. When overlaid against the process and relevant skills of taking 
raw data to tangible outcomes, we can observe which of these competencies need to be used at different parts of this process (Figure 10). Interestingly, the beginning of the process needs predominately hard skills, whereas the end of the process requires softer skills. Any BI change an organisation is wanting to embark on will follow a process similar to this. Based on the feedback related to these competencies at different stages of Kotter's model, the following suggestions are made to strengthen the process from turning data to business outcomes into Kotter's model:

1. Form the guiding coalition with people across all required competencies for turning data into outcomes.

2. Allow all members of the guiding coalition to be part of forming the vision and establishing the sense of urgency.

3. All parties in the guiding coalition should be responsible for the communication of the vision and ensuring short-term wins to their respective teams in a consistent manner.

4. Ensure the required technical proficiency is available, particularly to facilitate the 'Data' to 'Information' stages.

5. Check in with people who understand the business strategies and processes, to ensure the change is being institutionalised.

\section{Data to Outcome Process}

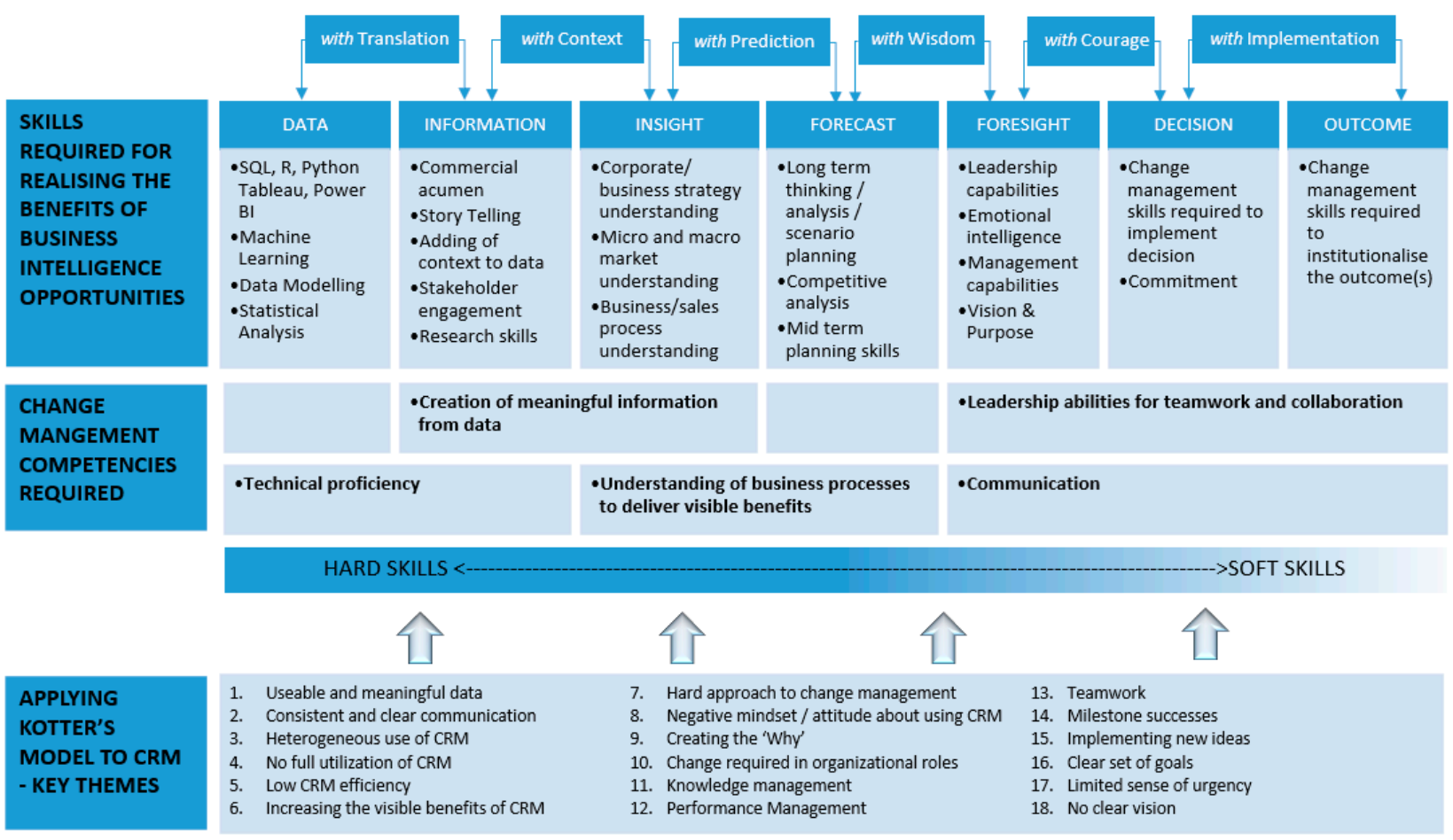

Figure 10. Overlaying the process and skills needed to turn data to business outcomes with the change management skills required, as developed for this study.

The proposed model encapsulates the importance of a variety of competencies which is often not found in one or two people alone, and therefore it is posited that a specific set of people with these specific competencies must be involved in CRM BI change programs to make it successful and to reduce risk. Yeoh and Popovic (2016) supported this, indicating that a BI project needs a balanced team to deliver value faster. The proposed model also addresses the identified criticism with Kotter's model that it is too rigid (Appelbaum et al. 2012) by confirming that people may need to jump in-between stages (Pollack and Pollack 2015) at any time during the change process.

Commonalities with the Key Success Factors (KSF) discussed earlier and the themes, created in the qualitative analysis, can also be found; for example: 
1. KSF, overall system performance (Hackney et al. 2015; Yeoh and Popovic 2016; Gaardboe and Svarre 2018), and the theme 'CRM efficiency'.

2. KSF, net benefits of the user (Hackney et al. 2015; Gaardboe and Svarre 2018), and the theme 'Increasing the visible benefits of CRM'.

3. KSF, information quality (Hackney et al. 2015; Yeoh and Popovic 2016; Gaardboe and Svarre 2018) and the theme 'data quality'.

The five competencies have linkages to existing literature in BI and change management. For example, Isson and Harriott (2012) believed that BI strategies should be first grounded in key business questions, and other authors state that there needs to be an alignment between business and data strategies (Lapide 2014; Henke et al. 2016) and how data can enhance them complementing the competency, 'Delivering visible benefits through the understanding of strategy and business processes. When executing this competency, it is important to consider that different users will see different benefits in the system (Levy et al. 2009) and, therefore, the creation of the vision and planning of short-term wins (Kotter 1996) need to be considered.

Because of the evidence that a relationship between employee satisfaction and management communication exists (Nelissen and van Selm 2008), communication of the strategy, vision and successes needs to follow Kotter's definition of a vision-'a picture of the future with some implicit or explicit commentary on why people should strive to create that future' - to ensure the communications match the value drivers for all users.

The competencies 'creation of meaningful information from data' and 'technical proficiency' are usually only discussed briefly in traditional change management literature, if at all. However, in this study we have discovered these skills are essential to CRM BI change management. Combining the literature with the results of the study infers that the skills gap which has been identified by several authors (Manyika et al. 2011; Williams 2011; Henke et al. 2016; Watson 2017) and the level of alignment to business strategy, has a direct impact on the ability of businesses to create meaningful information from data. Moreover, Watson et al. (2016) recognised that, due to the complexity and longevity of BI projects, it may be necessary to break large projects into smaller ones.

Finally, 'leadership skills with teamwork and collaboration' expands on Kotter's desire to have a guiding coalition with the power, expertise, credibility and leadership by honing in on the importance of the team, as most CRM BI change projects affect a variety of people within an organisation.

With regards to the data to outcome process, the challenge for businesses is to know the business outcomes required so that the vision can be created and communicated. Leadership teams of organisations who often create these visions for businesses are often strong in soft leadership skills; however, they may lack the technical expertise to understand what is possible with their data. Therefore, it will be imperative in the future for businesses to have representation within the senior leadership levels from someone who can translate technical possibilities to the vision and strategies of the business. Without this representation at a senior management level, it is likely that the guiding coalition would not have the power or credibility to influence the change possibilities within businesses.

\subsection{Further Research}

Results from this study provide insight into a specific use case, and therefore similar research could be conducted across multiple business and BI platforms to increase generalisation. The outcomes from this research provide a relevant reference point from which to test hypotheses regarding how important these competencies are to other data-driven change projects and reduce the many risks inherent in most change processes. Further to this, more research could be conducted to granulise the elements which contribute to the development of the identified competencies to understand how they could be developed within organisations and to provide a finer definition. Additionally, researching the agile impact methodology may have on the adapted change process of a CRM BI project 
could provide further depth to these results, which could be useful for academics and practitioners alike.

\section{Conclusions}

The intent of this research was to adapt an already well-known and recognised model within the CRM BI context, currently in use in the case organisation, so that it can be realistically implemented within the case organisation and other business environments to minimise risk and enhance the chance of change success.

This study has addressed the gap which Trieu (2017) identified of limited literature evaluating the change process when introducing BI systems within organisations and addressed the concern Appelbaum et al. (2012) had that there needs to be a greater emphasis on producing research in a useable form for practitioners.

Key competencies developed through qualitative research are supported by, and adds to, existing literature. There is strong alignment between the key competencies developed and the root causes for failing change programs (Manyika et al. 2011; Williams 2011; Lapide 2014; Henke et al. 2016; Watson 2017; Haskins et al. 2020), Yeoh and Popovic's (2016) opinion that a balanced team is required for BI change programs and Key Success Factors (KSF) created for information systems (Hackney et al. 2015; Yeoh and Popovic 2016; Gaardboe and Svarre 2018). Results showed that using Kotter's change model is still relevant within the $\mathrm{BI}$ context, however additional considerations need to be made with respect to the breadth and depth of competencies required to make the change successful. However, since these competencies range from employing hard and soft skills, there is a low likelihood that all competencies can be found in only a few people, which could cause some challenges for businesses. A lack of adherence to Kotter's (1996) model when embarking on BI change programs has many notable managerial implications, and hence, elevated risk, including but not limited to:

(a) Sub-standard configuration of CRM software.

(b) End-users not being able to extract value from CRM.

(c) Little end-user belief in why CRM is being implemented.

(d) Poor data (created by end-users) will result in a greater risk of poor business decisions.

(e) Businesses could miss key market opportunities.

The results give industry practitioners the framework needed to successfully implement Kotter's change management model within the CRM BI context, which helps to minimise risk and bridge the gap between theory and practice.

Author Contributions: Conceptualization, D.S. and C.C.; methodology, D.S.; validation, C.C.; formal analysis, D.S.; investigation, D.S.; resources, D.S.; data curation, D.S.; writing-original draft preparation, D.S.; writing-review and editing, C.C.; supervision, C.C.; project administration, C.C. All authors have read and agreed to the published version of the manuscript.

Funding: This research received no external funding.

Institutional Review Board Statement: The study was conducted according to the guidelines of the Declaration of Helsinki, and approved by the Ethics Committee of the Australian Institute of Management (October 2017 approval).

Informed Consent Statement: Informed consent was obtained from all subjects involved in the study.

Data Availability Statement: The data presented in this study are available on request from the corresponding author. The data are not publicly available due to commercial and confidentiality issues.

Acknowledgments: The authors wish to acknowledge the support of the Australian Institute of Management Business School; to Rob Scott and BJ Scott for editing and to Violet Lazarevic-Sittrop for ongoing advice and support.

Conflicts of Interest: The authors declare no conflict of interest. 


\section{Note}

1 The basis of utilisation is compared with the defined 'desired utilisation' across hierarchies. The low, medium, and high groupings were calculated by a basic clustering algorithm in Tableau.

\section{References}

Al-Haddad, Serina, and Timothy Kotnour. 2015. Integrating the organizational change literature: A model for successful change. Journal of Organizational Change Management 28: 234-62. [CrossRef]

Apostolopoulos, Charalampos, George Halikias, Krikor Maroukian, and Georgios Tsaramirsis. 2016. Facilitating organisational decision making: A change risk assessment model case study. Journal of Modelling in Management 11: 694-721. [CrossRef]

Appelbaum, Steven H., Sally Habashy, Jean-Luc Malo, and Hisham Shafiq. 2012. Back to the future: Revisiting Kotter's 1996 change model. Journal of Management Development 31: 764-82. [CrossRef]

Axelrod, Richard. 2010. Terms of Engagement: New Ways of Leading and Changing Organizations. San Francisco: Berrett-Koehler Publishers.

Beer, Michael, and Nitin Nohria. 2000. Breaking the Code of Change. Boston: Harvard Business School Press Books.

Bell, Emma, Alan Bryman, and Bill Harley. 2019. Business Research Methods, 5th ed. Oxford: Oxford University Press.

Bordia, Prashant, Elizabeth Hunt, Neil Paulsen, Dennis Tourish, and Nicholas DiFonzo. 2004. Uncertainty during organisational change: Is it all about control? European Journal of Work and Organizational Psychology 13: 345-65. [CrossRef]

Brisson-Banks, Claire V. 2010. Managing change and transitions: A comparison of different models and their commonalities. Library Management 31: 241-52. [CrossRef]

Caldwell, Raymond. 2003. Change leaders and change managers: Different or complementary? Leadership E Organization Development Journal 24: 285-93.

Chen, Chwen Jen. 2021. SoTL enculturation guided by Kotter's model of change. International Journal for Academic Development 1-5. [CrossRef]

Cunningham, Evelyn. 2021. Artificial Intelligence-based Decision-Making Algorithms, Sustainable Organizational Performance, and Automated Production Systems in Big Data-Driven Smart Urban Economy. Journal of Self-Governance E Management Economics 9: 31-41. [CrossRef]

Davis, Ruth, Marek Vochozka, Jaromir Vrbka, and Octav Neguriă. 2020. Industrial Artificial Intelligence, Smart Connected Sensors, and Big Data-driven Decision-Making Processes in Internet of Things-based Real-Time Production Logistics. Economics, Management E Financial Markets 15: 9-15. [CrossRef]

Eisenhardt, Kathleen M., and Melissa E. Graebner. 2007. Theory Building from Cases: Opportunities and Challenges. Academy of Management Journal 50: 25-32. [CrossRef]

Fadzil, Ahmad Syahmi, Syed Jamal Mohamad, and Roshidi Hassan. 2017. Resistance to Change (RTC): A Taxonomical Perspective. International Journal of Management Reviews 2: 116-22.

Gaardboe, Rikke, and Tanja Svarre. 2018. Business Intelligence Success Factors: A Literature Review. Journal of Information Technology Management 29: 1-15.

Gartner. 2021. Analytics and Business Intelligence (ABI). Available online: https://www.gartner.com/en/information-technology/ glossary/business-intelligence-bi (accessed on 30 September 2021).

Garvin, David A., and Michael A. Roberto. 2005. Change through Persuasion. Harvard Business Review 83: $26-33$.

Haas, Mary R. C., Brendan W. Munzer, Sally A. Santen, Laura R. Hopson, Nathan L. Haas, Daniel Overbeek, William J. Peterson, James A. Cranford, and Robert D. Huang. 2020. \#DidacticsRevolution: Applying Kotter's 8-Step Change Management Model to Residency Didactics. The Western Journal of Emergency Medicine 21. [CrossRef]

Hackney, Ray A., Paul Dooley, Yair Levy, and James Parrish. 2015. Critical value factors in business intelligence systems implementation success: An empirical analysis of system and information quality. Paper presented at the International Conference on Information Systems, Fort Worth, TX, USA, December 13-16.

Haskins, Peter, Anca Georgeta Luțan, and Alina Tănase. 2020. Sustainable Value Creation Networks, Digitized Mass Production, and Networked Information-driven Technologies in Industry 4.0-based Manufacturing Systems. Economics, Management E Financial Markets 15: 37-43. [CrossRef]

Henke, Nicolaus, Jacques Bughin, Michael Chui, James Manyika, Tamim Saleh, Bill Wiseman, and Guru Sethupathy. 2016. The Age of Analytics: Competing in a Data-Driven World. Chicago: McKinsey \& Company.

Higgs, Malcolm, and Deborah Rowland. 2005. All changes great and small: Exploring approaches to change and its leadership. Journal of Change Management 5: 121-51. [CrossRef]

Isson, Jean-Paul, and Jesse Harriott. 2012. Win with Advanced Business Analytics: Creating Business Value from Your Data. Somerset: John Wiley \& Sons.

Jacobs, Ronald L. 2002. Institutionalizing organizational change through cascade training. Journal of European Industrial Training 26: 177-82. [CrossRef]

Kang, Sung Pil, Yan Chen, Vanessa Svihla, Amber Gallup, Kristen Ferris, and Abhaya K. Datye. 2020. Guiding change in higher education: An emergent, iterative application of Kotter's change model. Studies in Higher Education 1-20. [CrossRef]

Kerzner, Harold. 2018. Project Management Best Practices: Achieving Global Excellence, 4th ed. Hoboken: Wiley.

Kotter, John P. 1990. A Force for Change: How Leadership Differs from Management. New York: Free Press. 
Kotter, John P. 1996. Leading Change. Boston: Harvard Business School Press.

Kotter, John P. 2007. Leading Change: Why Transformation Efforts Fail. Harvard Business Review 85: 96-103.

Kouzes, James M., and Barry Z. Posner. 2011. Credibility: How Leaders Gain and Lose It, Why People Demand It. New York: John Wiley \& Sons.

Laine, Pertti, Päivikki Kuoppakangas, and Jari Stenvall. 2020. Change Strategy (CS): Is There Any? Nordic Journal of Business 69: 5-22.

Lapide, Larry. 2014. Visualization-Key to Predictive Business Analytics. Journal of Business Forecasting 33: 34-38.

LaValle, Steve, Eric Lesser, Rebecca Shockley, Michael S. Hopkins, and Nina Kruschwitz. 2011. Big Data, Analytics and the Path from Insights to Value. MIT Sloan Management Review 52: 21-32.

Lawler, Edward E., III, and Christopher G. Worley. 2006. Built to Change: How to Achieve Sustained Organizational Effectiveness, 1st ed. San Francisco: Jossey-Bass.

Levy, Yair, Kenneth E. Murphy, and Stelios H. Zanakis. 2009. A Value-Satisfaction Taxonomy of IS Effectiveness (VSTISE): A Case Study of User Satisfaction with IS and User-Perceived Value of IS. International Journal of Information Systems in the Service Sector 1: 93-118. [CrossRef]

Manyika, James, Michael Chui, Brad Brown, Jacques Bughin, Richard Dobbs, Charles Roxburgh, and Angela Hung Byers. 2011. Big Data: The Next Frontier for Innovation, Competition, and Productivity. Chicago: McKinsey \& Company.

Maxwell, Joseph A. 2013. Qualitative Research Design: An Interactive Approach, 3rd ed. Thousand Oaks: SAGE.

Misra, Subhas C., Riya Rana, Ritika Verma, Vinod Kumar, and Uma Kumar. 2017. Modelling change management and risk management in a financial organization due to information system adoption. Transnational Corporations Review/Kuaguo Gongsi 9: 248-68. [CrossRef]

Nelissen, Paul, and Martine van Selm. 2008. Surviving organizational change: How management communication helps balance mixed feelings. Corporate Communications: An International Journal 13: 306-18. [CrossRef]

Nethravathi, Periyapatna Sathyanarayana Rao, Gokarna Vidya Bai, Cristi Spulbar, Mendon Suhan, Ramona Birau, Toni Calugaru, Iqbal Thonse Hawaldar, and Abdullah Ejaz. 2020. Business intelligence appraisal based on customer behaviour profile by using hobby based opinion mining in India: A case study. Economic Research-Ekonomska Istrazivanja 33: 1889-908. [CrossRef]

Pollack, Julien, and Rachel Pollack. 2015. Using Kotter's Eight Stage Process to Manage an Organisational Change Program: Presentation and Practice. Systemic Practice \& Action Research 28: 51-66. [CrossRef]

PricewaterhouseCoopers. 2015. Data Driven-What Students Need to Succeed in a Rapidly Changing Business World. London: PricewaterhouseCoopers.

Saunders, Mark, Philip Lewis, and Adrian Thornhill. 2019. Research Methods for Business Students, 8th ed. Harlow: Pearson Education, Limited.

Stacey, Ralph. 2001. Complex Responsive Processes in Organizations: Learning and Knowledge Creation. London: Taylor \& Francis Group.

Stare, Aljaz. 2011. Reducing Negative Impact of Project Changes with Risk and Change Management. Zagreb International Review of Economics E Business 14: 71-85.

Suler, Petr, Laura Palmer, and Svitlana Bilan. 2021. Internet of Things Sensing Networks, Digitized Mass Production, and Sustainable Organizational Performance in Cyber-Physical System-based Smart Factories. Journal of Self-Governance E Management Economics 9: 42-51. [CrossRef]

The Research Society. 2021. Professional Standards. Available online: https://researchsociety.com.au/professional-standards/ standards (accessed on 30 September 2019).

Todnem, Rune. 2005. Organisational change management: A critical review. Journal of Change Management 5: 369-80. [CrossRef]

Trieu, Van-Hau. 2017. Getting value from Business Intelligence systems: A review and research agenda. Decision Support Systems 93: 111-24. [CrossRef]

Urbach, Nils, Stefan Smolnik, and Gerold Riempp. 2009. The State of Research on Information Systems Success. Business E Information Systems Engineering 1: 315-25. [CrossRef]

Watson, Hugh J. 2017. The Cognitive Decision-Support Generation. Business Intelligence Journal 22: 5-14.

Watson, Hugh J., Hauke Heier, Hans P. Borgman, and Fabiano G. Neves. 2016. BI Project Success Is in the Eye of the Beholder. Business Intelligence Journal 21: 5-9.

Weiss, Pnina G., and Su-Ting T. Li. 2020. Leading Change to Address the Needs and Well-Being of Trainees during the COVID-19 Pandemic. Academic Pediatrics 20: 735-41. [CrossRef]

Williams, Steve. 2011. 5 Barriers to BI Success and how to overcome them. Strategic Finance 93: 27-33.

Yeoh, William, and Ales Popovic. 2016. Extending the Understanding of Critical Success Factors for Implementing Business Intelligence Systems. Journal of the Association for Information Science \& Technology 67: 134-47. [CrossRef]

Yin, Robert K. 2017. Case Study Research and Applications: Design and Methods, 6th ed. Thousand Oaks: SAGE. 